\title{
How practitioners integrate decision triggers with existing metrics in conservation monitoring
}

Claire N. Foster ${ }^{1,}{ }^{*}$, Luke S. O'Loughlin ${ }^{1,}{ }^{*}$, Chloe F. Sato ${ }^{1}$, Martin J. Westgate ${ }^{1}$, Philip S.

Barton $^{1}$, Jennifer C. Pierson ${ }^{1,2}$, Jayne M. Balmer ${ }^{3}$, Gareth Catt ${ }^{4}$, Jane Chapman ${ }^{5}$, Tanya

Detto $^{6}$, Amy Hawcroft ${ }^{7}$, Glenys Jones ${ }^{8}$, Rodney P. Kavanagh ${ }^{9}$, Meredith McKay ${ }^{7}$, Deanna

Marshall ${ }^{10}$, Katherine E. Moseby ${ }^{11,12}$, Mike Perry ${ }^{7}$, Doug Robinson ${ }^{10,13}$, Julian A. Seddon ${ }^{14}$, Katherine Tuft ${ }^{11}$ \& David B. Lindenmayer ${ }^{1}$

${ }^{1}$ Fenner School of Environment and Society, The Australian National University, Canberra, ACT 2601, Australia

${ }^{2}$ Tidbinbilla Nature Reserve, ACT Government, Tharwa, Australia

${ }^{3}$ Department of Primary Industries, Parks, Water and Environment, Hobart, TAS 7000, Australia

${ }^{4}$ Kanyirninpa Jukurrpa, PO Box 504, Newman, WA 6753, Australia

${ }^{5}$ Department of Biodiversity, Conservation and Attractions, Kensington, WA 6151, Australia

${ }^{6}$ Christmas Island National Park, Christmas Island, 6798, Australia

7 Department of Conservation, New Zealand

${ }^{8}$ School of Land and Food - Geography \& Spatial Science, University of Tasmania, Hobart, TAS 7001, Australia

${ }^{9}$ Australian Wildlife Conservancy, GPO Box 4301, Sydney, NSW 2001, Australia

${ }^{10}$ Trust For Nature, Melbourne, VIC 3000, Australia

${ }^{11}$ Arid Recovery, Olympic Dam South Australia

${ }^{12}$ School of Biological, Earth and Environmental Sciences, University of New South Wales, Kensington, NSW 2052, Australia

${ }^{13}$ Department of Ecology, Environment and Evolution, La Trobe University, Bundoora, VIC 3086, Australia

${ }^{14}$ ACT Environment, Planning and Sustainable Development Directorate, GPO Box 158, Canberra, ACT 2601, Australia

*Both authors contributed equally (joint first and corresponding authors)

Corresponding authors: Luke O'Loughlin (luke.oloughlin@anu.edu.au), Claire Foster (claire.foster@anu.edu.au)

Keywords: decision thresholds, evidence-based management, indicators, monitoring, proxy, surrogates 


\section{ABSTRACT}

Decision triggers are defined thresholds in the status of monitored variables that indicate when to undertake management, and avoid undesirable ecosystem change. Decision triggers are frequently recommended to conservation practitioners as a tool to facilitate evidence-based management practices, but there has been limited attention paid to how practitioners are integrating decision triggers into existing monitoring programs. We sought to understand whether conservation practitioners' use of decision triggers was influenced by the type of variables in their monitoring programs. We investigated this question using a practitioner-focused workshop involving a structured discussion and review of eight monitoring programs. Among our case studies, direct measures of biodiversity (e.g. native species) were more commonly monitored, but less likely to be linked to decision triggers (10\% with triggers) than measures being used as surrogates ( $54 \%$ with triggers) for program objectives. This was because decision triggers were associated with management of threatening processes, which were often monitored as a surrogate for a biodiversity asset of interest. By contrast, direct measures of biodiversity were more commonly associated with informal decision processes that led to activities such as management reviews or external consultation. Workshop participants were in favor of including more formalized decision triggers in their programs, but were limited by incomplete ecological knowledge, lack of skilled staff, funding constraints, and/or uncertainty regarding intervention effectiveness. We recommend that practitioners consider including decision triggers for discussion activities (such as external consultation) in their programs as more than just early warning points for future interventions, particularly for direct measures. Decision triggers for discussions should be recognized as a critical feature of monitoring programs where information and operational limitations inhibit the use of decision triggers for interventions. 


\section{Introduction}

Conservation monitoring programs are needed to assess trends in biodiversity, evaluate management effectiveness, and detect ecosystem changes (Lindenmayer et al., 2013; Nichols and Williams, 2006). These programs play a critical role in informing decisions about when to intervene to conserve the things we value (Nichols and Williams, 2006; Westgate et al., 2013). However, programs often do not clearly articulate how monitoring information will prompt management actions, an oversight that can contribute to further biodiversity loss (Lindenmayer et al., 2013; Woinarski et al., 2017). Recently, significant focus has been placed on integrating decision triggers (see Table 1) into monitoring programs to facilitate evidence-based management (Addison et al., 2016; Cook et al., 2016; de Bie et al., 2018). Decision triggers represent a point, zone or threshold in the status of a measure that indicates when management is required to maintain or reinstate a desired ecosystem state (see Addison et al., 2016; Cook et al., 2016). Similar to other threshold and reference point concepts in evidence-based management, there are many technical and non-technical approaches for identifying decision triggers (e.g. Martin et al., 2009; Morrison, 2008).

The benefits of adopting decision triggers for facilitating timely management actions are widely recognised (Addison et al., 2016; Cook et al., 2016; Nichols and Williams, 2006), and methodologies for fitting decision triggers into existing management frameworks have been detailed (de Bie et al., 2018). Although practitioners view decision triggers as a valuable management tool (Cook et al., 2016), there can be substantial financial, political, and scientific barriers to implementation (Addison et al., 2016; de Bie et al., 2018). This means practitioners will adapt new tools to fit with existing programs, rather than substantially modify programs to fit with new management tools (Lindenmayer et al., 2011). While others have discussed approaches for developing indicators for decision triggers (see Addison et al., 2016; Cook et al., 2016; de Bie et al., 2018), there has been little exploration of how practitioners integrate decision triggers into the structure of existing monitoring programs where the variables being monitored are already established. Addressing this knowledge gap is necessary to enable researchers to better support practitioners to incorporate decision triggers into monitoring programs, potentially leading to important benefits for biodiversity conservation. 
A key aspect of monitoring programs that could influence the application of decision triggers is the types of variables that are measured and how these are used to indicate progress towards, or away from, program goals (Duelli and Obrist, 2003; Siddig et al., 2016). Indicators are evaluated based on how accurately they represent a goal (Driscoll et al., 2018), and can either be a direct measure, or a surrogate that is used to make inferences about the goal (see Table 1) (Lindenmayer and Likens, 2011). Monitoring programs may use a combination of surrogates and direct measures as indicators of their program goals. For example, vegetation structural features might be measured as a surrogate for the presence of a threatened species known to rely on those features, and/or used as a direct measure to inform a management objective related to vegetation restoration (Lindenmayer et al., 2014; Pierson et al., 2015). Existing work suggests that both surrogate measures and the indicators that underpin decision triggers must be representative of the attribute of interest, responsive, and cost-effective to monitor (Addison et al., 2016; Lindenmayer et al., 2015). Surrogate measures may therefore be more easily adapted to use with decision triggers than direct measures. However, uncertainty in the relationship between surrogates and the target could also discourage practitioners from using surrogates to inform management interventions (O'Loughlin et al., 2018).

The aim of this study was to understand how practitioners integrate decision triggers into existing monitoring programs, and whether the application of decision triggers was associated with the types of variables being monitored. We held a workshop between conservation practitioners and researchers from Australia and New Zealand that addressed three questions: (1) To what extent do practitioners use decision triggers in their monitoring programs? (2) What kinds of measures and goals are commonly associated with decision triggers? and (3) What factors have limited the successful implementation of decision triggers, both for surrogates and for directly measured variables? We synthesise the outcomes of our workshop and highlight the difficulties often associated with integrating decision triggers for on-ground interventions into existing monitoring programs. We discuss how formally setting threshold points for discussion activities (e.g. review of management, external consultation, commissioning of research), particularly for direct measures of biodiversity assets, can increase the use of such measures for evidence-based management. 


\section{Approach}

We employed a case-study approach, comprising a workshop including 15 conservation practitioners, and focussing on eight case study monitoring programs. Our workshop was held in August 2017 and involved practitioners representing 10 government and nongovernment organisations from Australia and New Zealand. Practitioners were responsible for monitoring and managing a variety of ecosystems (tropical to temperate, forest to desert), across a range of spatial scales (from 10s to 100000 s of square $\mathrm{km}$ ), on both public and private land. All practitioners were involved in one of the eight case study monitoring programs.

The eight case study programs all aimed to inform biodiversity management and were established between 1 and 20 years ago (median $=6.5$ years). Three of the eight case studies included reserve-wide (or multi-reserve) monitoring programs, three were focused on a particular management issue, and the remaining two were sub-components of largerscale monitoring programs. One to three practitioners represented each program. Practitioners were responsible for one or more of the following activities: program design and implementation, providing scientific advice, collecting monitoring data and on-ground management.

During the workshop, practitioners conceptualised their monitoring programs using a predefined framework so that comparable information was generated for all programs (see Fig. 1). The framework asked practitioners to consider monitored variables in terms of how they informed the management goals of the program. This process involved creating a list of measures (these could be simple or summary measures, e.g. occurrence of bird species or bird species richness), a list of goals (these could be focussed or aspirational, e.g. increased occurrence of threatened birds or to conserve biodiversity) and then linking measures to the goal they were meant to inform (Fig. 1, Table 1). Measures could have links to multiple goals and similarly, goals could be informed by multiple measures. No program consisted only of single measures informing single goals, with all programs instead conceptualized as interlinked networks of varying complexity (see Fig. 1). Most measures identified by 
practitioners were measures of biodiversity assets (e.g. abundance of a native species) or threats (e.g. the frequency of fire), but some programs also included measures of drivers of threats (e.g. high rainfall and the resulting high biomass density can be driver of large, hot wildfires, but is not a threat in itself).

Once links between measures and goals were established for each program, information related to the relationship between the measure and the goal, existing decision triggers and potential decision triggers were added. First, each link between a measure and a goal was identified as either a direct measure or a surrogate, or both (see Table 1 for definitions). For example, measuring the abundance of the introduced European rabbit (Oryctolagus cuniculus) would be considered a direct measure when informing a goal related to decreased abundance of invasive species, or considered a surrogate when informing a goal related to improved vegetation cover (see Fig. 1).

Second, practitioners identified which links between measures and goals included an existing formalised decision trigger. Each decision trigger was classified based on whether the action initiated was an on-ground management intervention or a discussion activity (see Table 1). Third, practitioners identified on which links there were 'potential triggers' that represented cases where decisions had been made in the past (via informal processes) based on changes in monitored variables (see Table 1). Each potential trigger was also classified based on activity (intervention vs discussion) meaning four different types of triggers were documented (i.e. intervention decision trigger, discussion decision trigger, intervention potential trigger or discussion potential trigger). For example, an intervention decision trigger could be to initiate feral predator control at a particular predator density, whereas a discussion potential trigger might be to engage with researchers if vegetation condition is declining despite management of known threats.

These conceptualisations of the program structures were then collated, summarised and descriptive statistics calculated across the eight case studies. Descriptive statistics rather than quantitative analyses were used due to the type of data collected and the relatively small number of case studies employed. Our approach was designed to capture the 
collective experiences of participants in detail, rather than as a randomised and replicated quantitative study.

Following the conceptualisation exercise, we used facilitated discussion to elicit practitioner perspectives on when and where surrogate measures are most and least useful for informing decisions (including examples from their experiences), the advantages and disadvantages of using formalised decision triggers, and factors that limit development and/or implementation of decision triggers in their monitoring programs. This discussion did not produce quantitative data. Findings we present from this exercise represent the issues that practitioners agreed were both important and consistent among programs.

\section{Insights into the use of decision triggers and associated metrics}

\subsection{Question 1: How often are decision triggers used?}

Practitioners identified 66 measures linked to 48 different goals across the eight different monitoring programs, with individual programs consisting of 3-15 measures linked to 3-9 goals (Fig. 2a,b). Most measures (59\%) were direct measures of program goals (e.g. counts of native plants and animals to inform a goal of conserving biodiversity). Surrogates were also used by most programs (e.g. measures of vegetation structure or invasive species to inform a target related to native fauna), with $20 \%$ of measures used only as surrogates, and $15 \%$ used as both surrogate and direct measures for different management goals. The proportion of measures used as surrogates (for one or more goals) varied substantially among programs (from 0 to $80 \%$ of measures, median $=35 \%$ ). Practitioners expressed a preference for direct measures, reflected by the majority of goals being informed by direct measures only (56\%), compared to those informed only by surrogates $(16 \%)$, or by a combination of surrogate and direct measures (25\%).

Five monitoring programs included decision triggers and potential triggers, one included only potential triggers and the remaining two included none (Fig. 2a). Across the eight programs, practitioners identified a total of 15 decision triggers, linked to $17 \%$ of all measures and $27 \%$ of all goals. A further 18 potential triggers were identified across the 
programs, which, if developed into formalized decision triggers, would mean an additional $16 \%$ of all measures and $15 \%$ of all goals would be linked with decision triggers. Overall, the programs that measured fewer variables tended to have higher proportions of measures with triggers (Fig. 2a). Similarly, triggers tended to be attached to goals in higher proportions where programs had fewer goals (Fig. 2b). This potentially reflected differences between programs focused strongly on a few key issues with known management interventions (e.g. the control of an invasive predator with a culling program), and those with broader biodiversity conservation goals, where it may not be possible or appropriate to pre-identify management interventions for all goals.

\subsection{Question 2: What kinds of measures and goals are decision triggers used for?}

The majority of decision triggers in our case study programs were attached to surrogates (66\%), were for interventions (60\%), and all were attached to a measure of a threat or a driver of threat (Fig. 2c). In contrast, potential triggers were most often associated with direct measures (78\%), measures of biodiversity assets (61\%) and were most often for discussion activities (61\%) (Fig. 2d). These results indicate that goals informed by surrogate measures (which were usually measures of threats) were more likely to have decision triggers than goals informed by direct measures of a biodiversity asset. Fourteen of the 15 identified decision triggers were for the planning and implementation of control programs for invasive or overabundant species. The most common intervention action was to initiate a control program if high densities of introduced mammals were detected. In contrast, most potential triggers for discussions were to review management and research options if a particular native species was in decline.

The pattern of attaching decision triggers for intervention to threats and having potential triggers for discussion linked to biodiversity assets probably reflects three factors. First, practitioners' focus on actively managing threats as a means of protecting conservation assets. Developing decision triggers is likely to be simpler for threats, as desirable and undesirable states can be easily distinguished, and appropriate management interventions can often be pre-identified (Fig. 3a). For example, where practitioners were managing a fenced reserved that sought to be predator-free, any damage to the fence infrastructure or 
detection of an invasive predator triggered actions including fence repairs, additional monitoring, and targeted predator removal. In contrast, for many biodiversity assets, desirable and undesirable states may be difficult to identify (e.g. distinguishing natural fluctuations from problematic population change), and pre-identifying effective management interventions may not be possible or appropriate (Fig. 3a). For example, where the reason for a change in abundance of a native animal may not be clear, practitioners were cautious to set thresholds and actions for risk of implementing a management intervention that could make things worse.

Second, practitioners considered a representative and responsive surrogate as more capable of facilitating a timely response to a potential management issue. For example, in a situation where both a native species (e.g. bird abundance) and a key threat (e.g. rat predation) are monitored, a trigger attached to the direct measure of the native species could leave managers insufficient time to respond if a decline is observed. This is particularly the case for rare or cryptic native species where monitoring data are often sparse, and the power to detect population declines is limited (Nielsen et al., 2009). The problem with relying solely on native species as monitoring variables is clearly illustrated by the recent extinctions of the Christmas Island pipistrelle (Pipistrellus murrayi) and forest skink (Emoia nativitatis) (Woinarski et al., 2017). The likely threats to these species - introduced giant centipedes (Scolopendra subspinipes) and wolf snakes (Lycodon capucinus) - were not monitored (Smith et al., 2012), and declines in the species themselves were recognized too late to implement effective interventions. Failure to monitor appropriate surrogates in situations where changes in native species might be difficult to detect may leave insufficient time to organize an effective management response.

Third, attaching decision triggers to surrogates allowed some practitioners to balance monitoring and management priorities. Managers are often required to monitor specific ecosystem attributes for legislative, licensing or reporting purposes. For example, permit applications to cull pest animals often require robust estimates of pest numbers. Managers are therefore required to regularly monitor pest animal numbers which may divert resources away from monitoring of species of conservation concern. Where a required measure (e.g. rabbit abundance) can be identified as a surrogate for an attribute of interest 
(e.g. habitat condition for a native species), monitoring of the surrogate can allow managers to reduce monitoring of the attribute of interest, and meet both monitoring and management objectives within limited project budgets and time-frames.

The association we observed in our case studies between decision triggers and surrogates is not surprising given the preference practitioners expressed for evidence-based management approaches, and the similar depth of ecosystem knowledge required to develop both surrogates and decision triggers. The intrinsic uncertainty present with using a surrogate to inform a management goal (compared with using a direct measure) did not appear to deter practitioners from implementing decision triggers in conjunction with surrogate measures. The willingness of practitioners to link surrogates and decision triggers could reflect the need to justify management intervention with clear and documented ecological relationships. Whether or not decision triggers attached to surrogates have improved outcomes for biodiversity compared with triggers attached to direct measures is an important question for future research.

\subsection{Question 3: What factors have limited the integration of decision triggers into existing monitoring programs?}

Across the eight monitoring programs, only $16 \%$ of identified measures and $27 \%$ of management goals were linked with decision triggers (Fig. 2a,b). All practitioners expressed a desire to formalize at least some of the potential triggers in their monitoring programs, but similarly to Addison et al. (2016), practitioners identified incomplete ecological knowledge, inflexible and insufficient funding, and staffing limitations as key barriers to achieving this. We briefly discuss each of these barriers with the aim of highlighting additional insights gained through our workshop.

Practitioners expressed a preference for implementing evidence-based land-management, and highlighted ecosystem complexity and the limitations of single metrics as a problem in implementing decision triggers for some goals. For example, one program had previously used vegetation cover as a measure of ecosystem restoration. However, vegetation cover can change dramatically due to rainfall, temperature, abundance of native and exotic 
herbivores, fire, changes in floristic composition and the presence of weeds (e.g. Hejda et al., 2009), and so alone was an unreliable measure of the success of vegetation restoration efforts. Decision triggers attached to single measures are a practical approach to designing monitoring and management programs, yet their usefulness may be limited due to the complexity of the ecosystem processes responsible for environmental change. Techniques to include multiple measures within a decision trigger would allow practitioners to use these tools more extensively in their monitoring programs.

Consistent with previous work, practitioners identified funding constraints as a significant barrier to integrating more decision triggers into monitoring programs (Addison et al., 2016; Westgate et al., 2013). However, it was not simply a lack of funds, but inflexibility in funding models that was a particular barrier to implementing decision triggers for many organisations. Decision triggers and their associated metrics require considerable initial investment in research, development and stakeholder consultation, costs which are justified by expected improvements in cost-efficiency and management effectiveness. However, fixed budgets may not allow sufficient funding to be held in contingency for when a trigger point is reached, leaving little scope to specify decision triggers for expensive management actions. Practitioners agreed that a paradigm shift away from short-term and pre-allocated funding was necessary to enable more surrogates and decision triggers to be included in their programs. This is supported by recent research that found improved conservation outcomes where practitioners had greater control over when rather than just how to spend their limited resources (lacona et al., 2017).

A shortage of staff with the quantitative skills to develop decision triggers or verify surrogate relationships, along with high staff turnover and associated loss of local knowledge, were also identified as key barrier to integrating these tools into existing monitoring programs. Clear, well designed decision triggers can assist inexperienced practitioners in decision making, and avoid the shifting baselines syndrome that is exacerbated by high staff turnover (Papworth et al., 2009). Similarly, well-developed surrogates can enable simpler and more cost-effective data collection that is less reliant on technical expertise. For example, one program measured seed rain as an early warning trigger for predator control. This surrogate was useful because the relationship between 
seed rain and subsequent increases in predator abundance is well demonstrated (O'Donnell and Phillipson, 1996), and increases in seed rain can be detected earlier, more easily and more cost-effectively than changes in predator numbers. Investment in developing robust decision triggers and surrogates should be prioritized as a means of improving the stability and robustness of conservation monitoring and management programs in the face of staff turnover and loss of technical skills.

Importantly, practitioners highlighted that even without the barriers outlined above, there are three key reasons why not all monitoring variables should necessarily have decision triggers attached: (1) Covariates and contextual variables can be important for their potential future value within a monitoring program, even if not used to directly inform management. For example, consistently collected data on vegetation structure may help to form the evidence-base required to develop new decision triggers and surrogates in the future. Similarly, while a decision trigger to initiate management may be linked with a measure of a threat (e.g. invasive predator density), other measures of the ecosystem (e.g. vegetation, rainfall, etc.) can be critical to informing whether, and how, actions are undertaken. (2) A program that includes decision triggers on all monitored variables may be insufficiently responsive to unexpected events. Some practitioners stated that including too many decision triggers in a program risked committing them to particular actions or approaches, potentially limiting their capacity to adapt to changing priorities, funding conditions, or to new information. Emerging threats, like disease in a captive breeding population (Rose et al., 2017) or establishment of a new invasive species (Ricciardi et al., 2017) require rapid responses even if they have not been planned for in management schedules. (3) Practitioners expressed concerns that overly prescriptive programs risk stifling initiative and motivation among staff, reducing the likelihood of them observing and responding to unanticipated ecosystem changes.

\section{The value of decision triggers for discussions}

Decision triggers can be a valuable tool for establishing an evidence base for decisions, providing a defined pathway for initiating interventions, and ensuring monitoring is focused on informing targeted goals (Cook et al., 2016; Lindenmayer et al., 2013). The decision 
triggers approach resonates with conservation practitioners. Yet for many, current knowledge of their focal ecosystem, understanding of the relationships between variables and goals, and the quality/quantity of monitoring data are inadequate to pre-identify trigger points for many variables. We found that this was particularly true for direct measures of biodiversity assets, where distinguishing population trends from background fluctuation can be challenging, and management actions needed to recover declining populations often remain unknown. However, having pre-defined trigger points for biodiversity assets is one of the most tractable ways that organizations can act to prevent problems of shifting baselines and "monitoring to extinction" that can lead to declines or extinctions (Woinarski et al., 2017). We therefore suggest that increasing the use of decision triggers by setting trigger points for discussion activities (not just for on-ground management interventions) is an important step in improving evidence-based management of native species (Fig. 3b).

Triggers for discussion activities are often described as early-warning points that precede a more serious trigger for on-ground management intervention (de Bie et al., 2018). Among our case study programs, the greatest potential for increasing the use of decision triggers was in attaching triggers for discussions to measures independently of intervention triggers, particularly for goals where appropriate interventions cannot be pre-identified. This is required to avoid a situation, such as is illustrated in Figure 3, where a native species is declining, but the key threat is below the decision trigger threshold, meaning no management is initiated. Triggers for discussion activities can relate to activities such as consultation with external organizations, review of current management, or collection of additional data. Because the activities triggered are not direct management interventions, discussion triggers can be set despite the presence of knowledge, personnel and financial constraints that may obstruct the use of decision triggers for interventions.

Including decision triggers for discussions in monitoring programs requires predetermined trigger thresholds or trends to be formally stated within the program systems, and for these triggers to be linked with a predetermined response (e.g. consultation with partner agencies, commissioning of further research). For many programs this process would be as simple as explicitly documenting activities that are currently being undertaken informally (e.g. the potential triggers discussed above). Formalizing these potential triggers would 
allow practitioners to gain many of the benefits of the decision triggers model, including having a pre-defined point to escalate an issue, not relying on expert staff to identify and act on changes, having a consistent framework within which monitoring data are used, and ensuring management actions are documented and evaluated. We see triggers for discussion activities as a useful intermediate step for organizations that want to set decision triggers for more of the measures in their monitoring program (and particularly for direct measures of biodiversity assets), but are unable to set triggers for on-ground interventions because of structural, funding or knowledge constraints.

\section{Conclusions}

We used case studies and structured discussions between conservation practitioners and researchers to investigate how decision triggers are being used in existing long-term biodiversity monitoring programs, and how these related to different types of monitored variables and management goals. While we focused on monitoring programs from Australia and New Zealand, the patterns and issues we identified were consistent across organizations and programs, despite dissimilarities in ecosystems, organization structures and goals. This suggests that the issues identified are likely to be problems for conservation practitioners elsewhere. However, additional patterns and challenges may also occur in other regions, particularly in different socio-political and legislative contexts. We therefore encourage practitioners and researchers globally to have these kinds of discussions in order to better understand the value and practical limitations of new conservation tools.. In particular, the approach we used to conceptualize monitoring programs, explicitly mapping measures to goals (Fig. 1), proved useful for practitioners to critically assess and compare their programs, and represents a highly-transferable framework that could be applied to any monitoring program.

We found that practitioners most commonly used decision triggers in association with surrogate measures and measures of threats, likely because of organizational focus on threat management. Whether decision triggers attached to surrogate measures have beneficial outcomes for biodiversity is an important question for future research. Decision triggers were rarely attached to direct measures of biodiversity, and we suggest that 
increased use of decision triggers for discussion activities should be used to overcome some of the information and operational barriers driving this pattern (Fig. 3). However, while formalizing those potential triggers could be a useful stepping stone for many organizations, major changes to conservation funding models are needed to enable organizations to implement best-practice evidence-based management (Waldron et al., 2017). Overwhelmingly, practitioners are motivated to implement evidence-based management that is informed by robust, well-tested measures and decision triggers, but lack the commitment of resources to fully realize this, and the benefits this could bring to biodiversity management.

\section{Acknowledgements}

This research was funded by the Australian Research Council through a Laureate Fellowship to DBL. Tabitha Boyer and Claire Shepherd assisted with many aspects of workshop organization. Liana Joseph (AWC) and Mel Schroder (NSW OEH) contributed to workshop design. This manuscript was improved by comments from Jim Nichols and six anonymous reviewers.

\section{References}

Addison, P.F.E., Cook, C.N., de Bie, K., 2016. Conservation practitioners' perspectives on decision triggers for evidence-based management. J. Appl. Ecol. 53, 1351-1357. https://doi.org/10.1111/1365-2664.12734

Cook, C.N., de Bie, K., Keith, D.A., Addison, P.F.E., 2016. Decision triggers are a critical part of evidence-based conservation. Biol. Conserv. 195, 46-51.

https://doi.org/10.1016/j.biocon.2015.12.024

de Bie, K., Addison, P.F.E., Cook, C.N., 2018. Integrating decision triggers into conservation management practice. J. Appl. Ecol. 55, 494-502. https://doi.org/10.1111/13652664.13042

Driscoll, D.A., Bland, L.M., Bryan, B.A., Newsome, T.M., Nicholson, E., Ritchie, E.G., Doherty, T.S., 2018. A biodiversity-crisis hierarchy to evaluate and refine conservation indicators. Nat. Ecol. Evol. 2, 775-781. https://doi.org/10.1038/s41559-018-0504-8 
Duelli, P., Obrist, M.K., 2003. Biodiversity indicators: The choice of values and measures. Agric. Ecosyst. Environ. 98, 87-98. https://doi.org/10.1016/S0167-8809(03)00072-0 Hejda, M., Pyšek, P., Jarošík, V., 2009. Impact of invasive plants on the species richness, diversity and composition of invaded communities. J. Ecol. 97, 393-403. https://doi.org/10.1111/j.1365-2745.2009.01480.x Hunter, M., Westgate, M., Barton, P., Calhoun, A., Pierson, J., Tulloch, A., Beger, M., Branquinho, C., Caro, T., Gross, J., Heino, J., Lane, P., Longo, C., Martin, K., McDowell, W.H., Mellin, C., Salo, H., Lindenmayer, D., 2016. Two roles for ecological surrogacy: Indicator surrogates and management surrogates. Ecol. Indic. 63, 121-125. https://doi.org/10.1016/j.ecolind.2015.11.049

lacona, G.D., Possingham, H.P., Bode, M., 2017. Waiting can be an optimal conservation strategy, even in a crisis discipline. Proc. Natl. Acad. Sci. 114, 10497-10502. https://doi.org/10.1073/pnas.1702111114 Lindenmayer, D., Pierson, J., Barton, P., Beger, M., Branquinho, C., Calhoun, A., Caro, T., Greig, H., Gross, J., Heino, J., Hunter, M., Lane, P., Longo, C., Martin, K., McDowell, W.H., Mellin, C., Salo, H., Tulloch, A., Westgate, M., 2015. A new framework for selecting environmental surrogates. Sci. Total Environ. 538, 1029-1038. https://doi.org/10.1016/j.scitotenv.2015.08.056

Lindenmayer, D.B., Barton, P.S., Lane, P.W., Westgate, M.J., McBurney, L., Blair, D., Gibbons, P., Likens, G.E., 2014. An empirical assessment and comparison of species-based and habitat-based surrogates: a case study of forest vertebrates and large old trees. PLoS One 9, e89807. https://doi.org/10.1371/journal.pone.0089807

Lindenmayer, D.B., Likens, G.E., 2011. Direct measurement versus surrogate indicator species for evaluating environmental change and biodiversity loss. Ecosystems 14, 4759. https://doi.org/10.1007/s10021-010-9394-6

Lindenmayer, D.B., Likens, G.E., Haywood, A., Miezis, L., 2011. Adaptive monitoring in the real world: proof of concept. Trends Ecol. Evol. 26, 641-646.

https://doi.org/10.1016/j.tree.2011.08.002

Lindenmayer, D.B., Piggott, M.P., Wintle, B.A., 2013. Counting the books while the library burns: why conservation monitoring programs need a plan for action. Front. Ecol. Environ. 11, 549-555. https://doi.org/10.1890/120220 Martin, J., Runge, M.C., Nichols, J.D., Lubow, B.C., Kendall, W.L., 2009. Structured decision 
making as a conceptual framework to identify thresholds for conservation and management. Ecol. Appl. 19, 1079-1090. https://doi.org/10.1890/08-0255.1

Morrison, L.W., 2008. The Use of Control Charts to Interpret Environmental Monitoring Data. Nat. Areas J. 28, 66-73. https://doi.org/10.3375/08858608(2008)28[66:TUOCCT]2.0.CO;2

Nichols, J.D., Williams, B.K., 2006. Monitoring for conservation. Trends Ecol. Evol. 21, 668673. https://doi.org/10.1016/j.tree.2006.08.007

Nielsen, S.E., Haughland, D.L., Bayne, E., Schieck, J., 2009. Capacity of large-scale, long-term biodiversity monitoring programmes to detect trends in species prevalence. Biodivers. Conserv. 18, 2961-2978. https://doi.org/10.1007/s10531-009-9619-1

O'Donnell, C.F.J., Phillipson, S.M., 1996. Predicting the incidence of mohua predation from the seedfall, mouse, and predator fluctuations in beech forests. New Zeal. J. Zool. 23, 287-293. https://doi.org/10.1080/03014223.1996.9518087

O’Loughlin, L.S., Lindenmayer, D.B., Smith, M.D., Willig, M.R., Knapp, A.K., Cuddington, K., Hastings, A., Foster, C.N., Sato, C.F., Westgate, M.J., Barton, P.S., 2018. Surrogates Underpin Ecological Understanding and Practice. Bioscience. https://doi.org/10.1093/biosci/biy080

Papworth, S.K., Rist, J., Coad, L., Milner-Gulland, E.J., 2009. Evidence for shifting baseline syndrome in conservation. Conserv. Lett. 2, 93-100. https://doi.org/10.1111/j.1755263X.2009.00049.x

Pierson, J.C., Barton, P.S., Lane, P.W., Lindenmayer, D.B., 2015. Can habitat surrogates predict the response of target species to landscape change? Biol. Conserv. 184, 1-10. https://doi.org/10.1016/j.biocon.2014.12.017

Ricciardi, A., Blackburn, T.M., Carlton, J.T., Dick, J.T.A., Hulme, P.E., lacarella, J.C., Jeschke, J.M., Liebhold, A.M., Lockwood, J.L., Maclsaac, H.J., Pyšek, P., Richardson, D.M., Ruiz, G.M., Simberloff, D., Sutherland, W.J., Wardle, D.A., Aldridge, D.C., 2017. Invasion science: a horizon scan of emerging challenges and opportunities. Trends Ecol. Evol. 32, 464-474. https://doi.org/10.1016/j.tree.2017.03.007

Rose, K., Agius, J., Hall, J., Thompson, P., Eden, J., Srivastava, M., Tiernan, B., Jenkins, C., Phalen, D., 2017. Emergent multisystemic Enterococcus infection threatens endangered Christmas Island reptile populations. PLoS One 12, e0181240. https://doi.org/10.1371/journal.pone.0181240 
Siddig, A.A.H., Ellison, A.M., Ochs, A., Villar-Leeman, C., Lau, M.K., 2016. How do ecologists select and use indicator species to monitor ecological change? Insights from 14 years of publication in Ecological Indicators. Ecol. Indic. 60, 223-230.

https://doi.org/10.1016/j.ecolind.2015.06.036

Smith, M.J., Cogger, H., Tiernan, B., Maple, D., Boland, C., Napier, F., Detto, T., Smith, P., 2012. An oceanic island reptile community under threat: the decline of reptiles on Christmas Island, Indian Ocean. Herpetol. Conserv. Biol. 7, 206-218.

Waldron, A., Miller, D.C., Redding, D., Mooers, A., Kuhn, T.S., Nibbelink, N., Roberts, J.T., Tobias, J.A., Gittleman, J.L., 2017. Reductions in global biodiversity loss predicted from conservation spending. Nature 551, 364-367. https://doi.org/10.1038/nature24295

Westgate, M.J., Likens, G.E., Lindenmayer, D.B., 2013. Adaptive management of biological systems: A review. Biol. Conserv. 158, 128-139.

https://doi.org/10.1016/j.biocon.2012.08.016

Woinarski, J.C.Z., Garnett, S.T., Legge, S.M., Lindenmayer, D.B., 2017. The contribution of policy, law, management, research, and advocacy failings to the recent extinctions of three Australian vertebrate species. Conserv. Biol. 31, 13-23.

https://doi.org/10.1111/cobi.12852 


\section{Tables}

Table 1. Definitions and categories of measures, goals and decision triggers practitioners used to conceptualise their monitoring programs.

\begin{tabular}{|c|c|}
\hline Term and categories & Definition \\
\hline Measure & $\begin{array}{l}\text { An attribute of an ecosystem (biotic or abiotic factor) that is monitored to } \\
\text { provide information. } \\
\text { Similar terms used in other studies: variable, metric, indicator }\end{array}$ \\
\hline Direct measure & $\begin{array}{l}\text { An ecosystem attribute measured to make inferences about that aspect of the } \\
\text { ecosystem (see Lindenmayer \& Likens 2011). }\end{array}$ \\
\hline Surrogate & $\begin{array}{l}\text { An ecosystem attribute measured and used to make inferences about another, } \\
\text { different aspect of the ecosystem (the attribute of interest or target attribute) } \\
\text { (see Lindenmayer et al. 2015; Hunter et al. 2016). } \\
\text { Similar terms used in other studies: proxy, indicator }\end{array}$ \\
\hline Goal & $\begin{array}{l}\text { A desired outcome of undertaking a monitoring and management program. } \\
\text { Similar terms used in other studies: targets, objectives }\end{array}$ \\
\hline Decision trigger* & $\begin{array}{l}\text { A point or zone in the status of a measure indicating when management action } \\
\text { is required to maintain a desired ecosystem state or address undesirable } \\
\text { ecosystem change (see Addison et al. 2016; Cook et al. 2016). Decision trigger is } \\
\text { formalized within a program (i.e. stated in program documents and consistently } \\
\text { applied), with quantitative thresholds, and pre-determined responses. } \\
\text { Similar term used in other studies: decision threshold }\end{array}$ \\
\hline Potential trigger & $\begin{array}{l}\text { A decision trigger that has not been fully realised. The point or zone in the } \\
\text { status of a measure indicating when management action is required to maintain } \\
\text { a desired ecosystem state or address undesirable ecosystem change is not } \\
\text { explicitly identified (see Addison et al. 2016; Cook et al. 2016). Decision trigger } \\
\text { has been used in the recent history of the program but is not formalized (i.e. not } \\
\text { recorded and consistently applied). May have less defined quantitative } \\
\text { thresholds, and/or rely upon the expert knowledge, experience and actions of } \\
\text { individuals. }\end{array}$ \\
\hline Activity & $\begin{array}{l}\text { The management action or activity that is undertaken in response to the point } \\
\text { or zone in the status of a measure being reached. }\end{array}$ \\
\hline Intervention & $\begin{array}{l}\text { Activity triggered is an on-ground management intervention (e.g. invasive } \\
\text { species control, vegetation restoration) that is activated in response to a pre- } \\
\text { defined point in a measure being reached. }\end{array}$ \\
\hline Discussion & $\begin{array}{l}\text { Activity triggered is anything other than on-ground management intervention, } \\
\text { typically a pre-defined meeting, evaluation, consultation or review activity with } \\
\text { internal staff or external stakeholders (e.g. review of management action, } \\
\text { review of monitoring, planning, policy evaluation, reporting, engaging with } \\
\text { researchers). }\end{array}$ \\
\hline
\end{tabular}

* Practitioners classified each decision trigger and each potential trigger as either an 'intervention' or 'discussion' meaning four specific types of triggers are considered in our study; Intervention Decision Trigger, Discussion Decision Trigger, Intervention Potential Trigger, and Discussion Potential Trigger. 


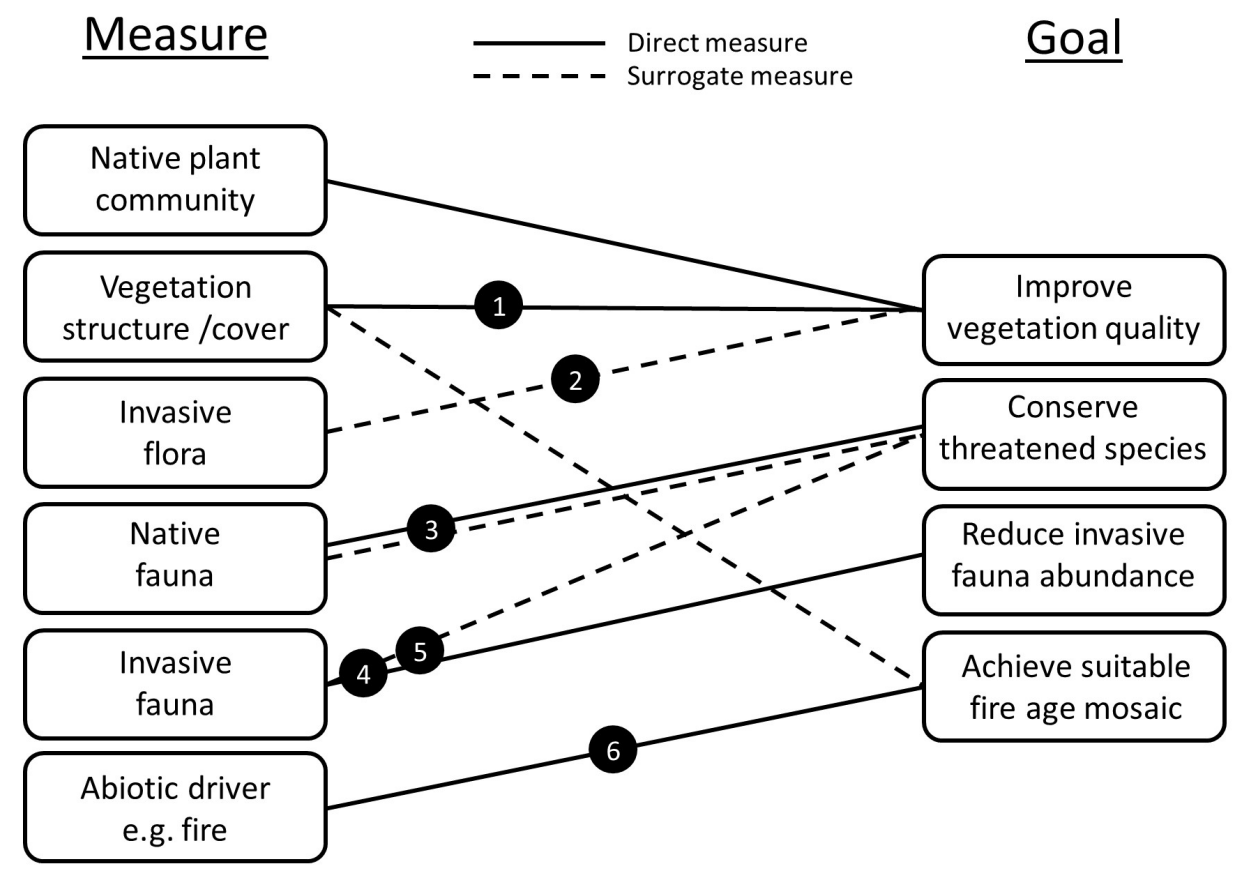

\section{$\underline{\text { Trigger }}$}

1 Decision trigger for discussion - ground cover decline below identified threshold triggers a review of management actions.

2 Decision trigger for intervention - cover of an invasive plant exceeds identified threshold and triggers targeted management (e.g. spraying).

3 Potential trigger for discussion - decline in native species occurrence triggers commissioning of research to identify drivers of decline.

4 Decision trigger for discussion - density of invasive animal exceeds identified threshold and triggers stakeholder meetings for control action.

5 Decision trigger for intervention - following 'discussion' activity, implementation of planned on-ground management actions (e.g. culling program).

6 Potential trigger for intervention - few recent fire events (as determined by expert-knowledge) triggers prescribed burning.

Figure 1. Representation of a 'typical' monitoring program discussed at the workshop, illustrating how measured variables link to management goals, what types of measures were used to link variables and goals (direct measures or surrogates), which links had decision triggers or potential triggers attached, and whether intervention or discussion activities were triggered (see Table 1 for definitions of classifications used). Our approach intentionally simplified a monitoring program down to its core components to (1) focus explicitly on how goals are informed by measures (not how measures inform other measures, or how goals inform other goals) and (2) allow comparison among dissimilar programs. 
a.

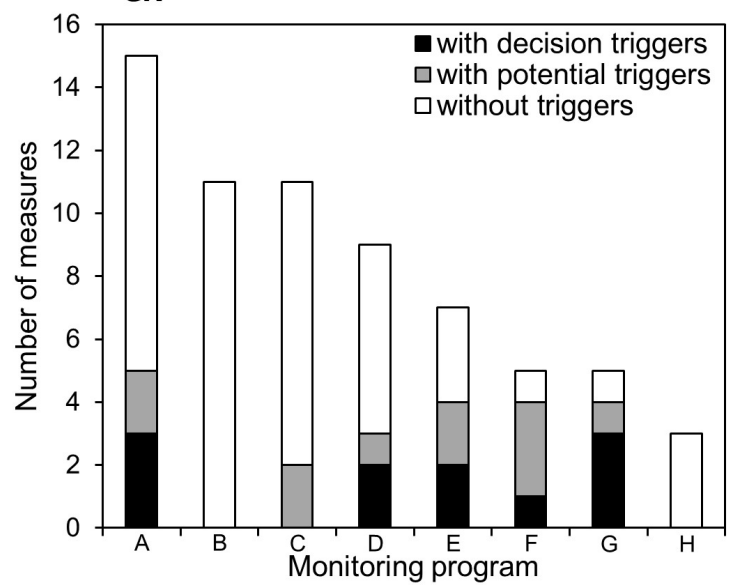

C.

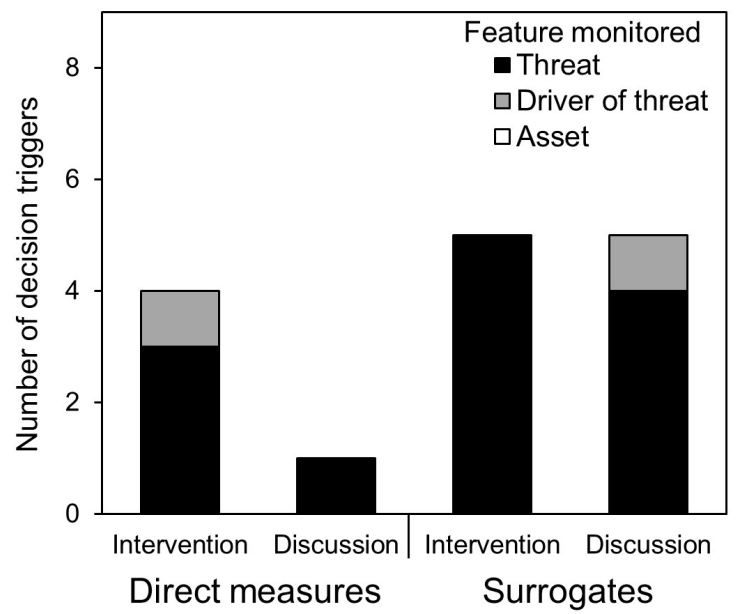

b.

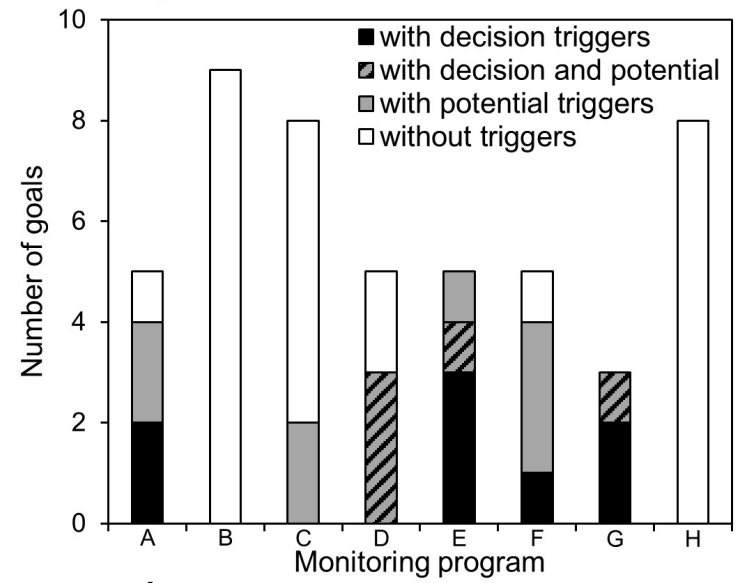

d.

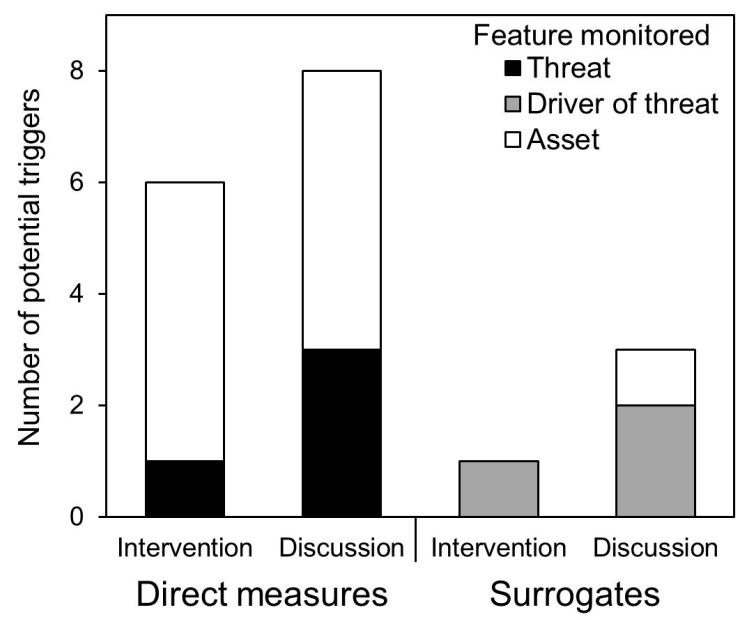

Type of measure and trigger

Figure 2. Summary of (a) the number measures and (b) the number of goals for each monitoring program and their association with decision triggers and potential triggers. Summary of (c) decision triggers and (d) potential triggers from across the monitoring programs in terms of the types of measures they are attached to and the activities triggered (see Table 1 for classifications and definitions). 

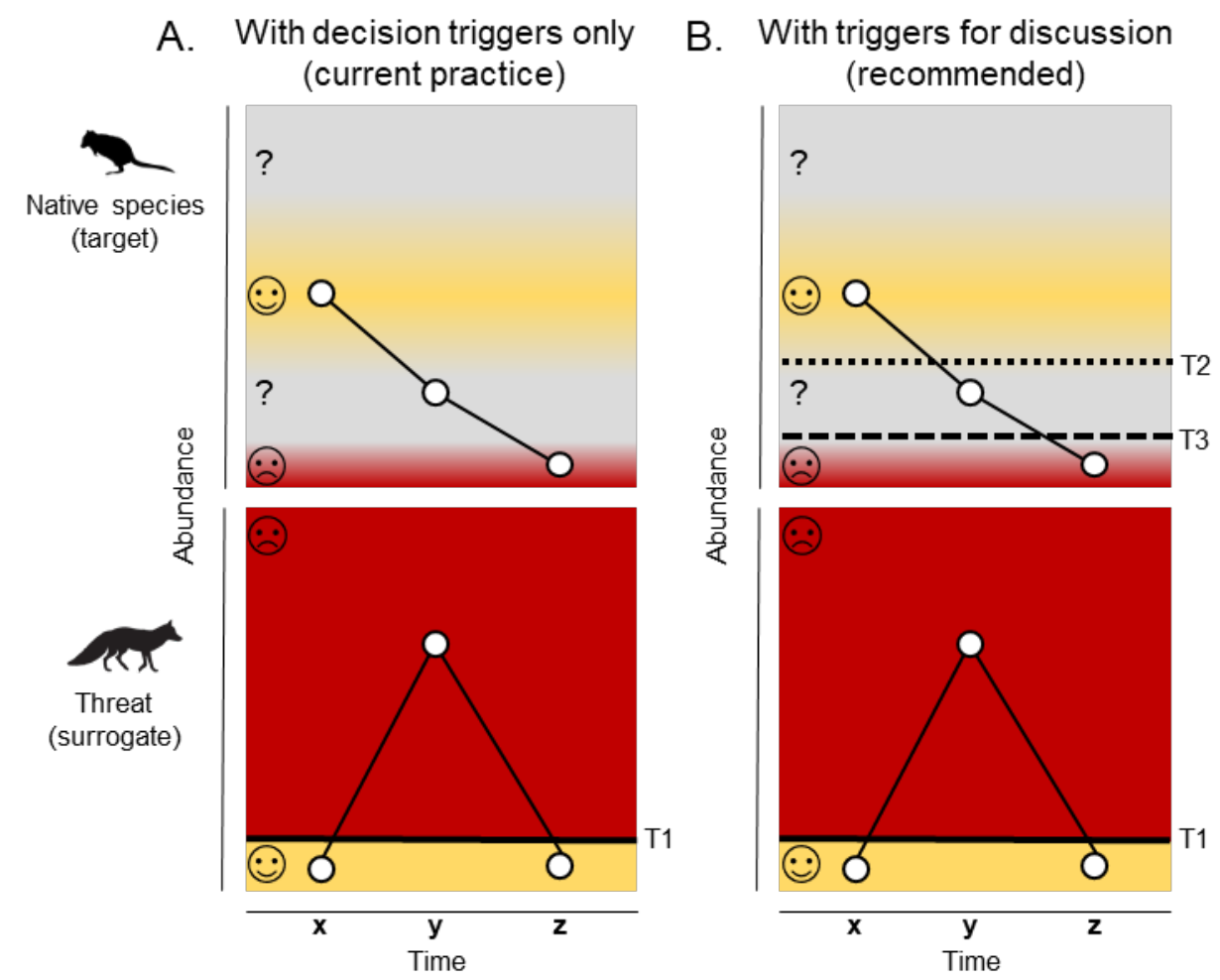

Figure 3. Simplified control charts (Morrison, 2008) illustrating the value of formalising decision triggers for discussion activities. For both the scenario in panel $A$ and in $B$, the program goal is to maintain or increase the abundance of a target native species, and a direct measure of the target (a native mammal species) and a surrogate (the primary threat, the red fox) are monitored. The scenario in panel A represents current practice for many organisations, where formal decision triggers are attached only to the surrogate measure of

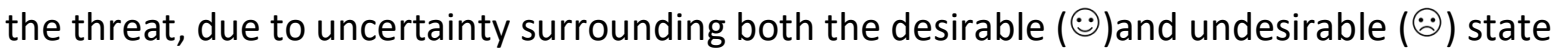
of the metric, and the lack of pre-identifiable management interventions. This is adequate when the predicted association between the target and the surrogate holds. For example, at time $\mathbf{x}$, both variables are in a desirable state and no actions are triggered. Then at time $\mathbf{y}$ the threat is in an undesirable state and an action is triggered ( $\mathrm{T} 1$ - initiate predator control). However, at time $\mathbf{z}$ the relationship between the target and the surrogate has broken down and surveys return a desirable state for the surrogate (the threat), but an undesirable state for the direct measure (the native species). In scenario A, where triggers are attached only to the threat, time $\mathbf{z}$ does not automatically trigger any action, and risks monitoring the target to extinction. However, in scenario $B$, where decision triggers are also attached to the direct measure of the target, the survey results at time $\mathbf{y}$ would trigger both T1 (predator control), and T2 (review of species monitoring and management), and a further decline of the native species at time $\mathbf{z}$ would also trigger T3 (emergency stakeholder meeting). 